\title{
Abnormalities of the Left Temporal Lobe and Thought Disorder in Schizophrenia
}

\section{Citation}

Shenton, Martha E., Ron Kikinis, Ferenc A. Jolesz, Seth D. Pollak, Marjorie LeMay, Cynthia G. Wible, Hiroto Hokama, et al. 1992. "Abnormalities of the Left Temporal Lobe and Thought Disorder in Schizophrenia." N Engl J Med 327 (9) (August 27): 604-612. doi:10.1056/ nejm199208273270905.

\section{Published Version}

doi:10.1056/NEJM199208273270905

\section{Permanent link}

http://nrs.harvard.edu/urn-3:HUL.InstRepos:28499625

\section{Terms of Use}

This article was downloaded from Harvard University's DASH repository, and is made available under the terms and conditions applicable to Other Posted Material, as set forth at http:// nrs.harvard.edu/urn-3:HUL.InstRepos:dash.current.terms-of-use\#LAA

\section{Share Your Story}

The Harvard community has made this article openly available.

Please share how this access benefits you. Submit a story.

\section{Accessibility}




\title{
ABNORMALITIES OF THE LEFT TEMPORAL LOBE AND THOUGHT DISORDER IN SCHIZOPHRENIA
}

\section{A Quantitative Magnetic Resonance Imaging Study}

\author{
Martha E. Shenton, Ph.D., Ron Kikinis, M.D., Ferenc A. Jolesz, M.D., Seth D. Pollak, M.A., \\ Marjorie LeMay, M.D., Gynthia G. Wible, Ph.D., Hiroto Hokama, M.D., John Martin, B.S., \\ Dave Metcalf, B.S., Michael Coleman, M.A., and Robert W. McGarley, M.D.
}

\begin{abstract}
Background. Data from postmortem, CT, and magnetic resonance imaging (MRI) studies indicate that patients with schizophrenia may have anatomical abnormalities of the left temporal lobe, but it is unclear whether these abnormalities are related to the thought disorder characteristic of schizophrenia.

Methods. We used new MRI neuroimaging techniques to derive (without knowledge of the diagnosis) volume measurements and three-dimensional reconstructions of temporal-lobe structures in vivo in 15 right-handed men with chronic schizophrenia and 15 matched controls.

Results. As compared with the controls, the patients had significant reductions in the volume of gray matter in the left anterior hippocampus-amygdala (by 19 percent [95 percent confidence interval, 3 to 36 percent]), the left parahippocampal gyrus (by 13 percent [95 percent confi-
\end{abstract}

CCHIZOPHRENIA is a disabling major mental $S$ disorder that is characterized by disordered thinking and hallucinations and that affects 1 percent of the population. Although its underlying pathologic process is still not clearly understood, recent postmortem investigations ${ }^{1-8}$ have revealed reductions in the volume of the medial limbic structures of the temporal lobe as well as abnormalities in the pattern of temporal-lobe gyri. ${ }^{9}$ Studies using magnetic resonance imaging (MRI) have also reported temporal-lobe abnormalities that have been localized in separate studies to volume reductions in the neocortical superior temporal gyrus and to limbic-system structures, including the amygdala, hippocampus, and parahippocampal gyrus. ${ }^{10-15}$ The volume reductions observed in both postmortem and MRI investigations have been most prominent on the left, and a similar lateralization of abnormalities has been reported in neurophysiologic, ${ }^{16-18}$ positron-emission tomographic, ${ }^{19,20}$ and attentional-processing studies, ${ }^{21}$ suggesting that abnormalities due to asymmetry are part of schizophrenia. ${ }^{22-24}$ However, the specific regional brain site (or sites) associated with the hallmark clinical symp-

From the Department of Psychiatry, Harvard Medical School, Boston, the Brockton Veterans Affairs Medical Center, Brockton, Mass., Massachusetts Mental Health Center, Boston, and McLean Hospital, Belmont, Mass. (M.E.S., S.D.P., C.G.W., H.H., M.C., R.W.M.); and the Department of Radiology, Harvard Medical School, and the MRI Division, Surgical Planning Laboratory, Brigham and Women's Hospital, both in Boston (R.K., F.A.J, M.L., J.M., D.M.). Address reprint requests to Dr. McCarley at the Department of Psychiatry-116A, 940 Belmont St., Brockton, MA 02401.

Supported in part by a Research Scientist Development Award (K01-MH00746-04 [Dr. Shenton]) from the National Institute of Mental Health, the Department of Veterans Affairs (Dr. McCarley), a grant (40,799 [Dr. McCarley]) from the National Institute of Mental Health, the Milton Foundation (Dr. Shenton), the Scottish Rite Foundation (Dr. Shenton), the Commonwealth of Massachusetts Research Center (Dr. McCarley), a Research Career Development Award (K04-NS-01083 [Dr. Jolesz]) from the National Institutes of Health, and the Swiss National Foundation (Dr. Kikinis). dence interval, 3 to 23 percent], vs. 8 percent on the right), and the left superior temporal gyrus (by 15 percent [95 percent confidence interval, 5 to 25 percent]). The volume of the left posterior superior temporal gyrus correlated with the score on the thought-disorder index in the 13 patients evaluated $(r=-0.81, P=0.001)$. None of these regional volume decreases were accompanied by a decrease in the volume of the overall brain or temporal lobe. The volume of gray matter in a control region (the superior frontal gyrus) was essentially the same in the patients and controls.

Conclusions. Schizophrenia involves localized reductions in the gray matter of the left temporal lobe. The degree of thought disorder is related to the size of the reduction in volume of the left posterior superior temporal gyrus. (N Engl J Med 1992;327:604-12.)

tom of thought disorder ${ }^{25}$ has remained undefined, although speculation has been plentiful.

Recently, a new generation of MRI techniques has made it possible to quantify the volume of both whole brain and small brain structures with an enhanced precision, ${ }^{26}$ allowing a more accurate and detailed assessment of limbic and neocortical anomalies. This development is particularly relevant to schizophrenia, in which abnormalities are more subtle than in other brain disorders and the imprecision of measurement ${ }^{27}$ may have contributed to the lack of uniformity of results in previous studies.

In this study we used computerized image-processing techniques to analyze thin-slice $(1.5 \mathrm{~mm}$ and $3 \mathrm{~mm}$ ) MRI scans with high spatial resolution in order to test our hypothesis that there is a specific link between the thought disorder present in schizophrenia and pathologic sites in the left temporal lobe, a hypothesis based on our earlier research ${ }^{28}$ that related positive symptoms to enlargement of the left sylvian fissure.

\section{Methods}

\section{Subjects}

We studied 15 right-handed men with chronic schizophrenia who were receiving neuroleptic medication equivalent to a mean of 881 mg of chlorpromazine per day; they were recruited from among patients at the Brockton Veterans Affairs Medical Center. Information from the Schedule for Affective Disorders and Schizophrenia ${ }^{29}$ and from chart reviews was used to determine their diagnoses according to the Diagnostic and Statistical Manual of Mental Disorders. ${ }^{30}$ Patients selected for study had to be 20 to 55 years old, have never undergone electroconvulsive shock treatment, have no history of neurologic illness, have no major alcohol or drug abuse in the previous five years, and have not been receiving medications known to affect the results of MRI of the brain, such as steroids.

The mean $( \pm \mathrm{SD})$ age of the patients at the time of testing was $37 \pm 9$ years, and the duration of their illness was $189 \pm 106$ months. Since the onset of schizophrenia they had been hospitalized $48 \pm 29$ 
percent of the time. Their mean score on the information subtest of the Wechsler Adult Intelligence Scale-Revised (WAIS-R) ${ }^{31}$ was $9.9 \pm 2.41$, and their score for the socioeconomic status of family of origin was $3.4 \pm 0.1$ ( 3 denotes a skilled craftsman or a clerical or sales worker). ${ }^{32}$

Fifteen men were recruited through newspaper advertisements to serve as controls; they were matched with the patients for age and handedness. These subjects were screened for disease factors that could affect brain function, including alcohol abuse, and none had a history of psychiatric or neurologic illness themselves, nor did their first-degree relatives. There were no statistically significant differences between the two groups in height, weight, head circumference, socioeconomic status of family of origin, or scores on the WAIS-R information subscale. ${ }^{31}$ All 30 subjects gave informed consent.

\section{Clinical Measures}

The patients were evaluated for both behavioral excesses, such as hallucinations, delusions, and formal thought disorder (positive symptoms), and behavioral deficits, such as anhedonia, alogia, and flat affect (negative symptoms). The Scale for the Assessment of Positive Symptoms ${ }^{33}$ and the Scale for the Assessment of Negative Symptoms ${ }^{34}$ were used to categorize their symptoms as mainly positive (11 patients), mainly negative (none of the patients), or mixed (4 patients). In addition, the Thought-Disorder Index ${ }^{35,36}$ was used to assess formal thought disorders in the patients; their mean score was $60.4 \pm 61.8$ (range, 1.7 to 214 ), whereas the average score of normal subjects ${ }^{35}$ is less than 5 (the controls were not tested). The reliability of these measures between raters has been shown to be quite high. ${ }^{18,36,37}$

\section{Image Acquisition}

MRI scanning was performed with a 1.5-tesla General Electric Signa System (GE Medical Systems, Milwaukee). Sagittal localizer images were obtained first, followed by double-echo spin-echo axial slices of whole brain. The repetition time was $3000 \mathrm{msec}$, the echo time 30 and $80 \mathrm{msec}$, the slice thickness $3 \mathrm{~mm}$, the field of view 24 $\mathrm{cm}$, and the acquisition matrix 256 by 256 (192 phase-encoding steps, with zero filling); conjugate synthesis was used in combination with an interleaved acquisition that resulted in 108 contiguous double-echo slices (54 levels). The voxel (volume of pixel) dimensions were 0.975 by 0.975 by $3 \mathrm{~mm}$.

For manual and semiautomated measurement of the temporal lobe, three-dimensional Fourier-transform (3DFT) spoiled-gradient-recalled acquisition was used because it affords excellent contrast between gray and white matter for the evaluation of temporallobe structures. The repetition time was $35 \mathrm{msec}$, the echo time $5 \mathrm{msec}$ with one repetition, the nutation angle 45 degrees, the field of view $24 \mathrm{~cm}$, and the matrix 256 by 256 (again, 192 phase-encoding steps) by 124 . Voxel dimensions were 0.975 by 0.975 by $1.5 \mathrm{~mm}$. The data were stored and analyzed as 124 coronal slices, each $1.5 \mathrm{~mm}$ thick. To reduce flow-related artifacts (due to cerebrospinal fluid and blood), gradient moment nulling and presaturation of a slab inferior to the head were performed during both the axial and 3DFT acquisitions. A clinical neuroradiologist evaluated the MRI scans and found no gross abnormalities in any subject.

\section{Image Processing}

\section{Whole Brain (Axial Acquisition)}

Image processing was carried out on workstations (Sun Microsystems, Mountain View, Calif.) with newly developed multistep algorithms, ${ }^{38-42}$ including a preprocessing filter to reduce noise without blurring fine morphologic details ${ }^{41,43}$; a segmentation algorithm to assign voxels to distinct classes (i.e., voxels representing cerebrospinal fluid, gray matter, white matter, and connective tissue or vessels) $^{38,39}$; a connectivity algorithm ${ }^{38-40}$ to define subsets of a particular class, such as cerebrospinal fluid in intraventricular, subarachnoidal, left and right lateral ventricular spaces, and in left and right temporal and occipital horns; a dividing-cubes algorithm to visualize different classes of tissue in three-dimensional space ${ }^{40}$; and a final summing of voxels for each tissue class to compute volumes (as described in detail elsewhere ${ }^{42,44-46}$ ). Preliminary data on seg-
Table 1. Anterior and Posterior Extent of Regions of Interest.

\begin{tabular}{|c|c|c|}
\hline REGION & Most ANTERIOR SLice & Most Postrrior SLICE \\
\hline $\begin{array}{l}\text { Amygdala-anterior } \\
\text { hippocampus }\end{array}$ & $\begin{array}{l}\text { White-matter tract (tempo- } \\
\text { ral stem) linking tempo- } \\
\text { ral lobe with rest } \\
\text { of brain }\end{array}$ & $\begin{array}{l}\text { Last slice before the appear- } \\
\text { ance of the mammillary } \\
\text { bodies }\end{array}$ \\
\hline $\begin{array}{l}\text { Posterior hippo- } \\
\text { campus }\end{array}$ & $\begin{array}{l}\text { First appearance of the } \\
\text { mammillary bodies }\end{array}$ & $\begin{array}{l}\text { Last appearance of fibers } \\
\text { of the crux of the fornix }\end{array}$ \\
\hline $\begin{array}{l}\text { Superior temporal } \\
\text { gyrus } \\
\text { Anterior region } \\
\text { Posterior region }\end{array}$ & \multicolumn{2}{|c|}{$\begin{array}{l}\text { Landmarks for amygdala-anterior hippocampus } \\
\text { Landmarks for posterior hippocampus }\end{array}$} \\
\hline $\begin{array}{l}\text { Parahippocampal } \\
\text { gyrus }\end{array}$ & \multicolumn{2}{|c|}{ Landmarks for superior temporal gyrus } \\
\hline $\begin{array}{c}\text { Temporal lobe } \\
\text { Anterior and } \\
\text { posterior } \\
\text { portions }\end{array}$ & \multicolumn{2}{|c|}{ Landmarks for superior temporal gyrus } \\
\hline Anterior pole & $\begin{array}{l}\text { Second slice showing } \\
\text { temporal lobe }\end{array}$ & $\begin{array}{l}\text { Slice immediately anterior to } \\
\text { start of superior temporal } \\
\text { gyrus and amygdala }\end{array}$ \\
\hline $\begin{array}{l}\text { Superior frontal } \\
\text { gyrus }\end{array}$ & $\begin{array}{l}\text { First appearance of } \\
\text { superior frontal gyrus }\end{array}$ & $\begin{array}{l}\text { First slice showing complete } \\
\text { crossing of anterior } \\
\text { commissure fibers }\end{array}$ \\
\hline
\end{tabular}

mentation of a phantom of a brain slice with these techniques showed that the error of measurement ranged from 4 to 6 percent. ${ }^{46}$

\section{Temporal Lobe (3DFT Acquisition)}

Table 1 defines the landmarks used to assess the regions of interest. The atlas of Daniels et al. ${ }^{47}$ was used as the primary anatomical guide for MRI. Neuroanatomical structures were outlined manually on a workstation display screen (Fig. 1), and volumes were calculated by summing voxels over all slices containing these structures. (More complete information on the definitions of the neuroanatomical regions of interest and on volumetric data for nonsignificant results is available through the National Auxiliary Publications Service.*)

One rater blinded to the patient's diagnosis measured the regions of interest. To evaluate the reliability of measurement, a second rater, also blinded to the diagnosis, measured the temporal-lobe regions of three controls and three patients randomly selected from each group. In addition, four raters blinded to the diagnosis assessed the superior frontal gyrus of one patient selected at random, after this region had been segmented into four parts ( 12 slices each). The average intraclass correlation $\left(r_{i}\right)$ was 0.86 .

\section{Statistical Analysis}

Volumetric analyses were corrected for intracranial volume to control for variations in head size. All statistical analyses were performed on corrected (relative) volumes, although for comparative purposes we present absolute values for volume. Statistical analyses of automated measurements of whole brain were performed with t-tests (two-tailed). The effects of laterality and region on the volumes of temporal-lobe structures were examined by a mixedmodel analysis of variance, with one "between factor" - group (patients vs. controls) - and two "within factors" - laterality (left vs. right) and region (anterior hippocampus or amygdala, posterior hippocampus, parahippocampal gyrus, and superior temporal gyrus). This analysis was followed by planned comparisons in which the $P$ value indicating statistical significance was set at $\leqslant 0.02$. A Wilcoxon matched-pairs signed-rank test was used to assess asymmetry between left and right volumes (significance level set at $\mathrm{P} \leqslant 0.02$ ).

*See NAPS document no. 04964 for seven pages of supplementary material. Order from NAPS c/o Microfiche Publications, P.O. Box 3513, Grand Central Station, New York, NY 10163-3513. Remit in advance (in U.S. funds only) $\$ 7.75$ for photocopies or $\$ 4$ for microfiche. Outside the U.S. and Canada, add postage of $\$ 4.50$ ( $\$ 1.75$ for microfiche postage). There is a $\$ 15$ invoicing charge for all orders filled before payment. 


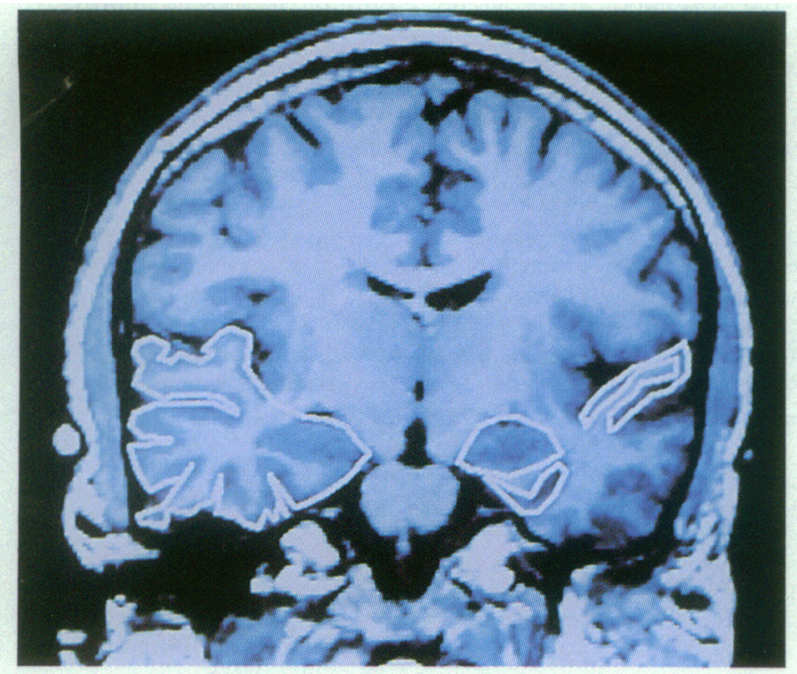

A

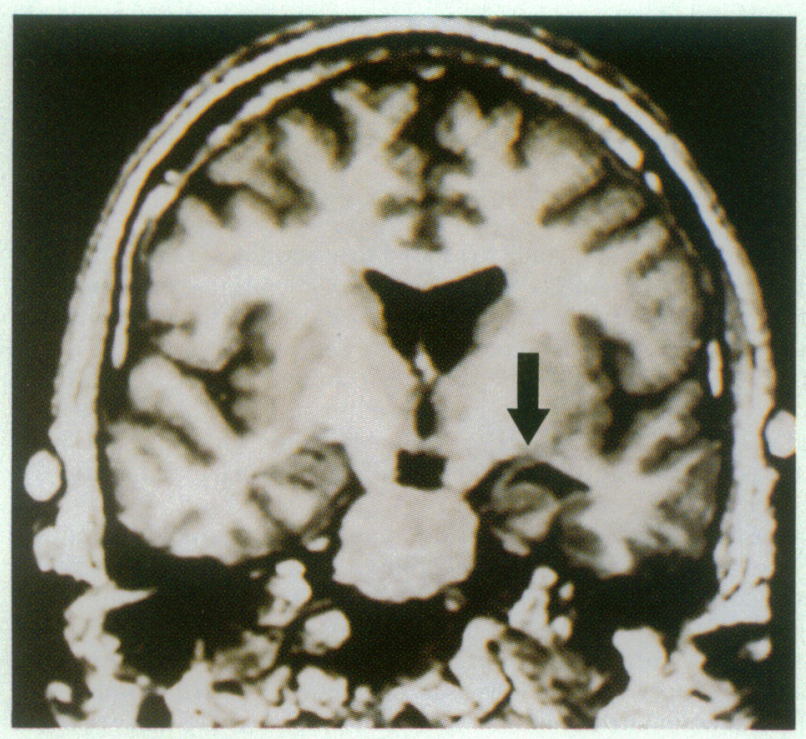

B

For Pearson correlations among neuroanatomical measurements within the study groups, two-tailed tests of significance were also used (the significance level was conservatively set at $P \leqslant 0.01$ ). Because age can affect volumetric measurement, even when the age range is restricted, ${ }^{48}$ an analysis of covariance for age was performed. This did not influence the results (no $\mathrm{P}$ values $\leqslant 0.05$ ); consequently, statistical analyses are presented without covariance for age.

\section{Results}

\section{Automated Segmentation of Whole Brain and Ventricular Spaces}

There were no significant mean differences between the two study groups in any measurements of wholebrain volumes (Table 2). Figure 2 shows the results of automated segmentation of the face, gray matter, and white matter as three-dimensional reconstructions viewed from different perspectives.

An assessment of homogeneity of variance with an F maximum-minimum test, in which the largest variance for a population is divided by the minimal variance for a population, revealed that the variance in the
Figure 1. Coronal Slice $(1.5 \mathrm{~mm})$ of the Temporal Lobe of a Control (Panel A) and a Patient with Schizophrenia (Panel B).

In Panel $A$ the regions of interest used to evaluate the temporal lobe (see text) have been outlined: the neocortical gray matter of the superior temporal gyrus is on the subject's left (the viewer's right); more medially, the amygdala-hippocampal complex is shown as an almond-like shape, with the parahippocampal gyrus underneath. The temporal lobe is outlined on the subject's right. In Panel B, the amount of cerebrospinal fluid (black area) surrounding the left superior temporal gyrus (sylvian fissure) is increased as compared with the amount in the control. Note also the tissue loss in the parahippocampal gyrus and the increase in the size of the temporal horn surrounding the amygdala-hippocampal complex (arrow).

volume of the lateral ventricles was greater among the patients than the controls $(F=6.87$, df $=1,28$; $\mathrm{P}<0.001)$; this difference was localized to the left lateral ventricles $(\mathrm{F}=14.8, \mathrm{df}=1,28 ; \mathrm{P}<0.001)$, but not the right $(\mathrm{F}=2.53, \mathrm{df}=1,28 ; \mathrm{P} \leqslant 0.1)$. Moreover, the volume of the left temporal horn was 180 percent larger in the patients than in the controls, and the right temporal horn was 74 percent larger $(P=0.04$ for the left and right horns; $P=0.004$ for both combined).

\section{Manually Guided Segmentation of Limbic-System Structures and Neocortical Superior Temporal Gyrus}

Analysis of variance revealed a significant threeway interaction among the factors of study group, laterality, and temporal-lobe region $(\mathbf{F}=3.94$, df $=3$, 84; $\mathrm{P}=0.01)$. Follow-up planned t-tests indicated that the volume of the left anterior hippocampus, left parahippocampal gyrus (also the right), and left superior temporal gyrus was significantly smaller in the patients than in the controls (Table 2 and Fig. 3). When the difference in volume was expressed as a percentage, the patients had a 19 percent reduction in the left anterior hippocampal-amygdala complex (95 percent confidence interval, 3 to 36 percent), a 13 percent reduction in the left parahippocampal gyrus (95 percent confidence interval, 3 to 23 percent) ( 8 percent on the right), and a 15 percent reduction in the left superior temporal gyrus (95 percent confidence interval, 5 to 25 percent). An example of the extent of tissue loss can be seen in Figure 1. No such differences were apparent in the volume of the left or right posterior hippocampus, right superior temporal gyrus, or right anterior hippocampus. When the dimensions of the anterior or posterior areas of these structures were examined, significant differences in the size of the amygdala-hippocampal complex and the superior temporal gyrus were noted (Table 2).* As compared with the controls, the patients had a significant reduction in the volume of the left anterior parahippocampal gyrus $(P \leqslant 0.002)$, but not in the volume of the posterior portion of this gyrus $(P<0.09)$. However, because the volume of the anterior segment was

*See NAPS document no. 04964 for seven pages of supplementary material. Order from NAPS c/o Microfiche Publications, P.O. Box 3513, Grand Central Station, New York, NY 10163-3513. Remit in advance (in U.S. funds only) $\$ 7.75$ for photocopies or $\$ 4$ for microfiche. Outside the U.S. and Canada, add postage of $\$ 4.50$ ( $\$ 1.75$ for microfiche postage). There is a $\$ 15$ invoicing charge for all orders filled before payment. 
so small $(<1 \mathrm{ml}$ in all subjects), the anterior and posterior segments were not analyzed further.

Figure 2 shows a three-dimensional reconstruction of the amygdala-hippocampal complex and the temporal lobe. Heschl's gyrus (primary auditory cortex) appears as a ridge bounded laterally by the more flattened planum temporale.

\section{Asymmetry and the Hippocampus, Parahippocampal Gyrus, and Superior Temporal Gyrus}

No left-right asymmetry was found among any of the temporal-lobe structures of the controls. In contrast, the patients had significant asymmetry, with reduced volume on the left side of the parahippocampal gyrus $(\mathbf{P}=0.012)$, anterior hippocampus-amygdala $(\mathrm{P}=0.001)$, and superior temporal gyrus $(\mathrm{P}<0.001)$. No such asymmetry was evident in the posterior hippocampus.

\section{Temporal Lobe}

There was no significant difference between the patients and controls when the volumes of the left and right temporal lobes or the volumes of the temporallobe subdivisions (i.e., the temporal pole and the anterior and posterior segments [Fig. 2]) were compared. Within each group of subjects, there was no significant difference between the left and right temporal lobes and their subdivisions.*

\section{Correlations among Temporal-Lobe Abnormalities}

In the patients, the volume of the left temporal horn correlated significantly and negatively with that of the left parahippocampal gyrus $(r=-0.70, P \leqslant 0.001$, two-tailed), and there was a trend $(P=0.02)$ toward a negative correlation between the volumes of the left temporal horn and left posterior hippocampus $(r=-0.61)$. In addition, the volume of the left parahippocampal gyrus positively and significantly correlated with that of the left posterior hippocampus $(r=0.65, P \leqslant 0.01)$. The volume of the left anterior superior temporal gyrus correlated positively and significantly with that of the left anterior hippocampus-amygdala complex $(\mathrm{r}=0.82, \mathrm{P} \leqslant 0.001)$. There was also a trend toward a positive correlation between the volumes of the left posterior superior temporal gyrus and the left parahippocampal gyrus $(\mathrm{r}=0.52, \mathrm{P} \leqslant 0.05)$. In contrast, no significant correlations were found among these temporal-lobe regions in the controls.

\section{Thought-Disorder Scores and Temporal-Lobe Volumes}

As shown in Figure 4, there was a strong negative correlation in the patients between the total thoughtdisorder score and the absolute volume of the left posterior superior temporal gyrus $(\mathrm{r}=-0.81, \mathrm{P}=0.001$; $\mathrm{r}=-0.78, \mathrm{P}=0.002$ for relative volume), indicating that 66 percent of the variance among the scores was explained by this relation. This association was best fit by a semilogarithmic plot, indicating that the total thought-disorder score increased exponentially as a function of the decrease in the volume of the left posterior superior temporal gyrus. Fig-
Table 2. Absolute Volumes of Automatically Segmented Regions of the Whole Brain and Manually Segmented Regions of the Temporal Lobe in 15 Patients with Schizophrenia and 15 Matched Controls.*

\begin{tabular}{ccc}
\hline \hline ReGion & Volume $(95 \% \mathrm{Cl})$ & P VAl.ue $\dagger$ \\
& $m l$ &
\end{tabular}

Whole brain

Total intracranial cavity

Controls

Patients

Gray matter

Controls

Patients

White matter

Controls

Patients

Subarachnoidal CSF

Controls

Patients

Third ventricle

Controls

Patients

Fourth ventricle

Controls

Patients

Lateral ventricles

Controls

Patients

Ventricle:brain ratio

Controls

Patients

$1562.1 \pm 104$.
$1621.5 \pm 109$.
$759.2 \pm 101.7$
$772.8 \pm 93.5$
$681.6 \pm 112$.
$730.4 \pm 102.7$
$104.5 \pm 29.2$
$96.8 \pm 39.4$
$2.1 \pm 0.89$
$2.0 \pm 0.62$
$1.6 \pm 0.50$
$1.4 \pm 0.55$
$13.1 \pm 4.18$
$17.1 \pm 10.6$
$9.2 \pm 3.0$
$11.3 \pm 6.4$

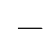

Temporal lobe

Left anterior hippocampus

Controls

Patients

Left parahippocampal gyrus

Controls

Patients

Right parahippocampal gyrus

Controls

Patients

Left superior temporal gyrus

Controls

Patients

Left anterior superior

temporal gyrus

Controls

Patients

Left posterior superior

temporal gyrus

Controls

Patients

$2.4 \pm 0.60 \%(2.0-2.7)$

$1.9 \pm 0.61 \quad(1.6-2.3)$

0.010

$2.2 \pm 0.26 \quad(2.1-2.4)$

$1.9 \pm 0.38 \quad(1.7-2.1)$

0.008

$2.2 \pm 0.28 \quad(2.1-2.4)$

$2.0 \pm 0.31 \quad(1.8-2.2)$

0.018

$7.3 \pm 0.97 \quad(6.8-7.9)$

$6.2 \pm 1.2 \quad(5.5-6.9)$

0.002

$1.5 \pm 0.37 \quad(1.2-1.7)$

$1.0 \pm 0.39(0.80-1.2)$

0.001

${ }^{*} \mathrm{Cl}$ denotes confidence interval, and CSF cerebrospinal fluid. Plus-minus values are means \pm SD. Only data on the temporal-lobe regions in which there were significant differences $\pm \mathrm{SD}$. Only data on the temporal-lobe
between the study groups are shown.

$\dagger$ The $P$ values reflect comparisons of relative (not absolute) volumes

$\ddagger$ The mean total brain volume (volume of gray and white matter, $1440.8 \mathrm{ml}$ ) reported here is consistent with the mean postmortem volume of $1430 \mathrm{ml}$ observed in males by Boyd ${ }^{49}$

$\S$ The mean volume for the lateral ventricles is consistent with the range of 9 to $35 \mathrm{ml}$ reported in the literature. ${ }^{50-52}$

TThe mean length of the amygdala-hippocampal complex (the value for the volume of the anterior portion is shown here) was calculated from manually segmented slices; the mean was $44 \mathrm{~mm}$ on the right and $41 \mathrm{~mm}$ on the left in the controls - values consistent with the range of 40 to $45 \mathrm{~mm}$ found in 60 adults post mortem. ${ }^{53}$

ure 2 shows that this region includes the planum temporale.

The specificity of the relation between the total thought-disorder score and the volume of the left posterior superior temporal gyrus was indicated by the absence of statistically significant correlations with other regions on both linear and semilogarithmic fits. A trend was observed for a linear correlation between the thought-disorder score and the volume of the right temporal horn $(\mathrm{r}=0.65, \mathrm{P}=0.017)$. There were 


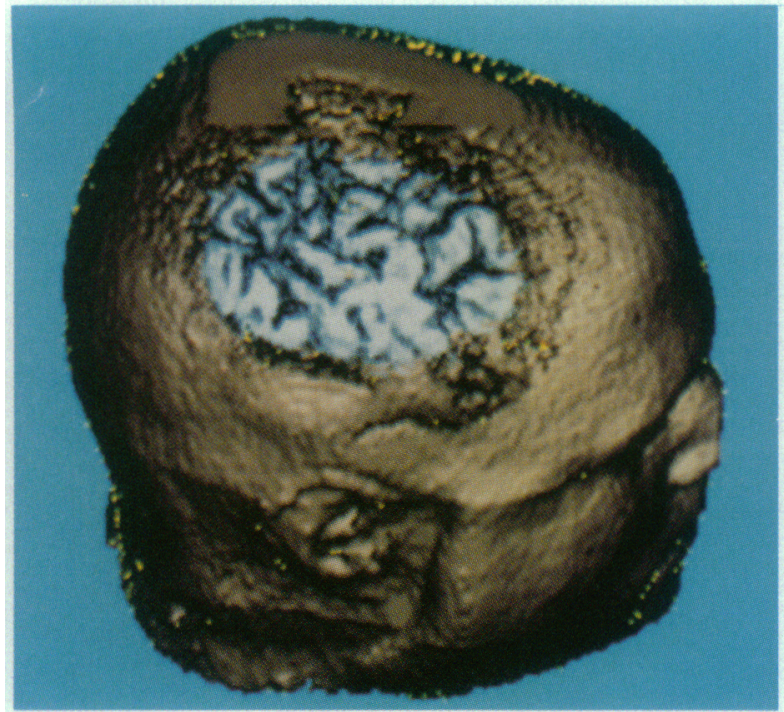

A

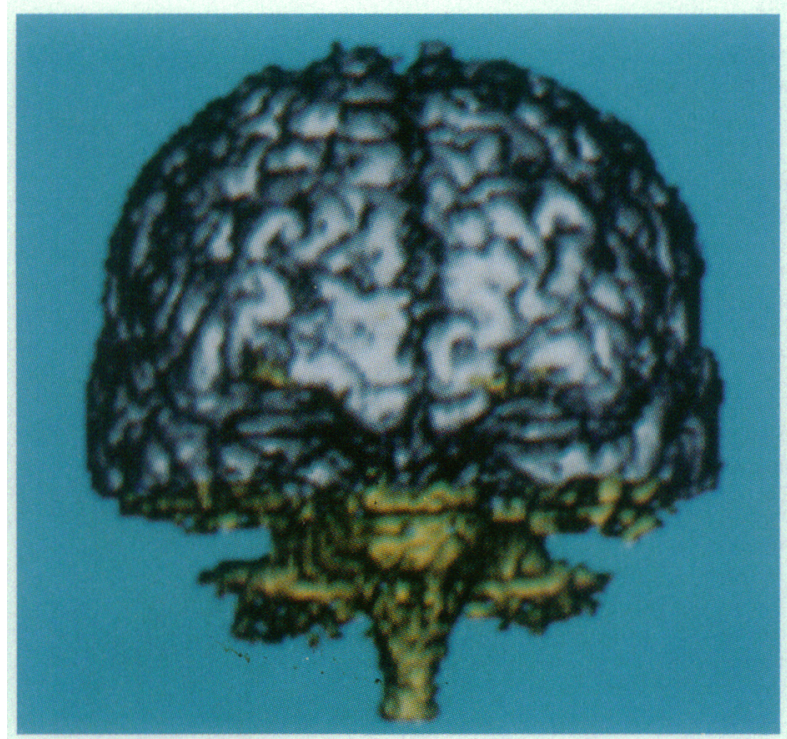

C

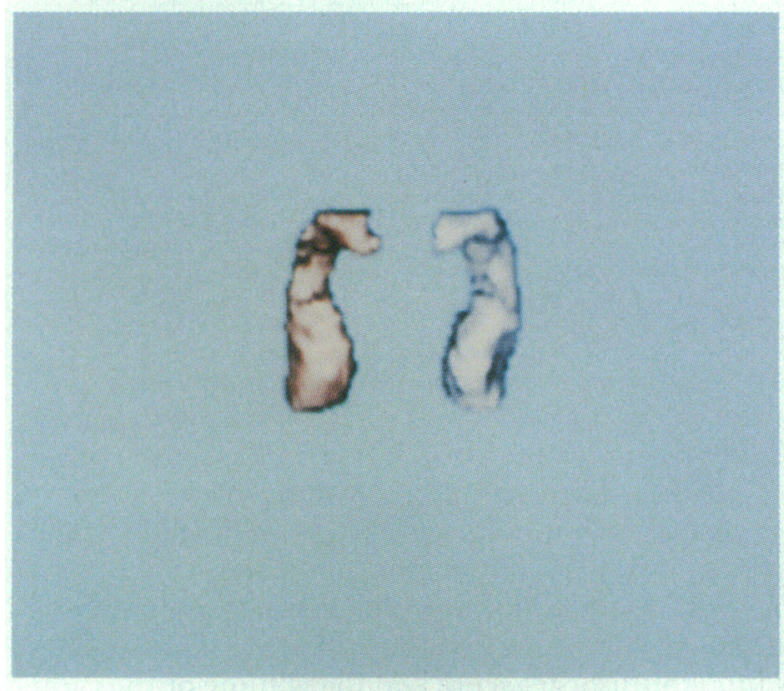

E

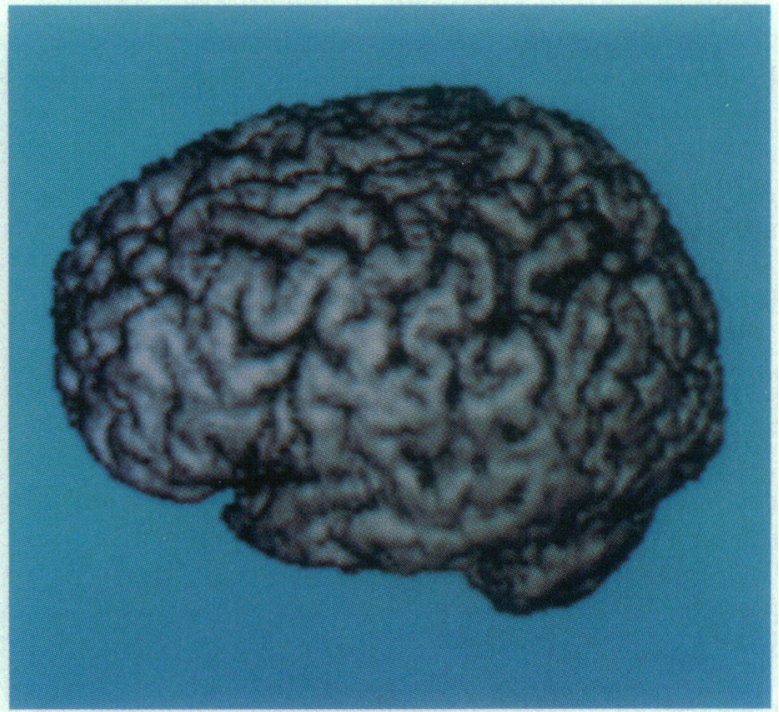

B

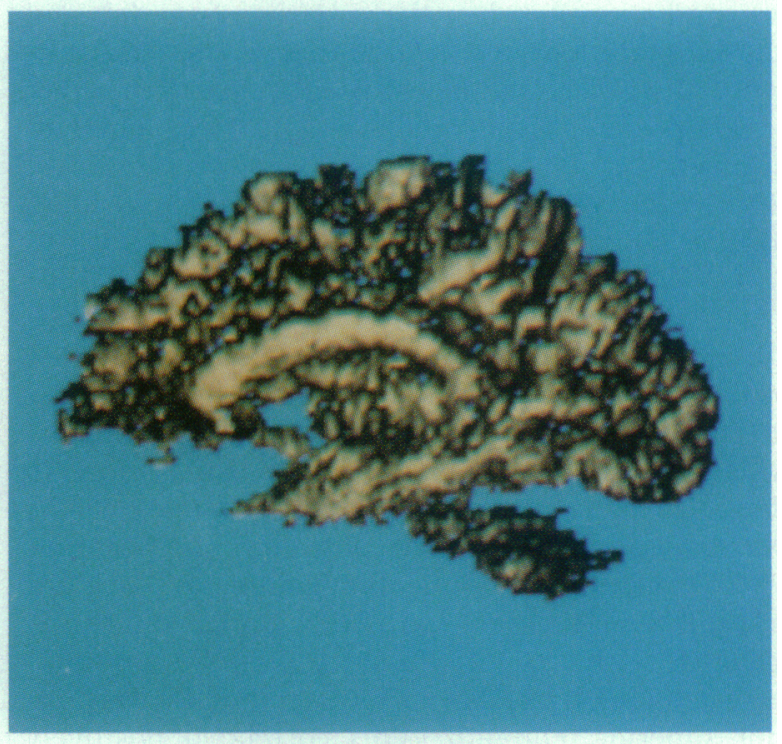

D

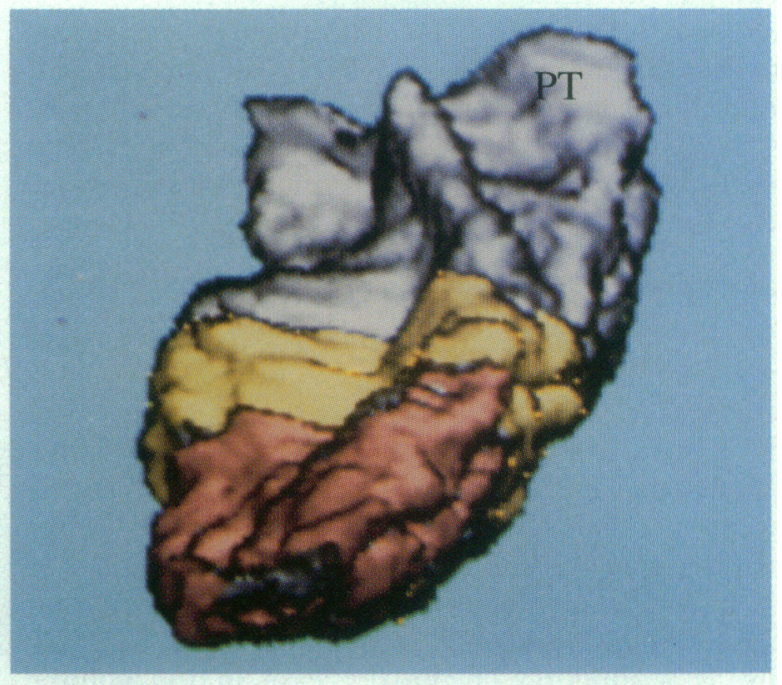

$\mathrm{F}$ 
no significant correlations with the volume of the control area - the gray matter of the superior frontal gyrus - in which there also was no significant difference between the controls and patients (controls, $22.7 \pm 3.7 \mathrm{ml}$ in the left gyrus and $23.0 \pm 3.1 \mathrm{ml}$ in the right; patients, $21.7 \pm 3.9 \mathrm{ml}$ in the left gyrus and $22.4 \pm 3.8 \mathrm{ml}$ in the right).

\section{Discussion}

Our study of schizophrenia with a new generation of neuroimaging techniques and quantitative MRI measurement of volume yielded three major findings. First, there was a lateralized (left sided) decrease in the volume of gray matter in the anterior hippocampusamygdala, parahippocampal gyrus, and superior temporal gyrus and a concomitant increase in the volume of the temporal horn of the lateral ventricles. Second, there was a strong correlation between the degree of thought disorder - a cardinal neurobehavioral symptom of schizophrenia - and the decrease in the volume of the left posterior superior temporal gyrus, a region long considered important as a neuroanatomical substrate of language. ${ }^{54-58}$ Third, in the patients there were statistically significant correlations among volume reductions in neuroanatomically interconnected temporal-lobe regions that may be important in forming auditory associative memory links. The patients and controls did not differ in total temporal-lobe volume or in automated volumetric measurements of the whole brain (gray and white matter), total cerebrospinal fluid, or ventricle:brain ratio ([lateral ventricle volume/total intracranial volume] $\times 100$ ). The findings of local but not global differences in the volumes can be explained by the variation among subjects in the volumes of large structures (e.g., a standard deviation of $7.4 \mathrm{ml}$ in the volume of the left temporal lobe in the controls). Such variation obscures the differences between the groups in the comparisons of the volumes of small local regions such as the left superior temporal gyrus, for which the absolute difference in volume between the patients and controls was only $1.1 \mathrm{ml}$.
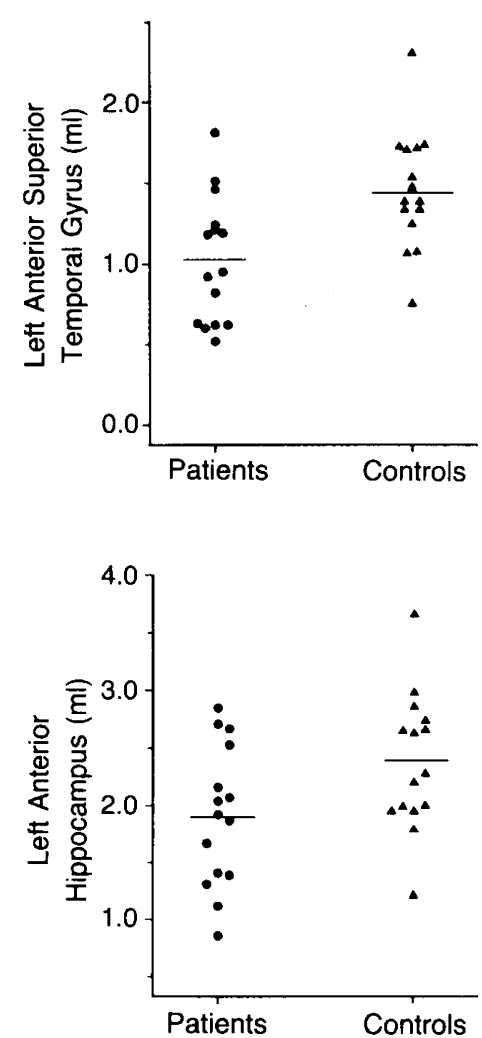

Patients

Controls

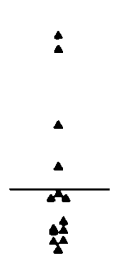

Controls

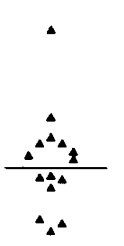

Controls

Figure 3. Volumes of the Regions of Interest in the Patients and Controls. The regions shown are those for which the means for the study groups (horizontal lines) differed most.

These findings confirm previous reports suggesting an association between temporal-lobe abnormalities and schizophrenia, and extend our knowledge by providing evidence of an absence of global brain atrophy, the presence of specific limbic-neocortical loci of the pathologic process, and a key clinicopathological correlation - that between the thought-disorder score and the reduction in the volume of the left posterior superior temporal gyrus. However, before any generalizations are drawn from these findings in a subgroup of 15 patients, some caveats are necessary. We do not yet know whether similar features are present in patients with other diagnoses, such as mood disorders with psychosis, or in patients with a first episode of schizophrenia, in whom the potential confounding effects of chronicity and medication may not have occurred.

As compared with manual segmentation, automated techniques for processing MRI scans increase reliability and reproducibility and greatly reduce analysis

Figure 2. Three-Dimensional Reconstructions and Rotations of Tissue Classes Defined by Automated Segmentation (Classification) Algorithms.

The tissue of the face (Panel A) is visualized with a (virtual) opening to the brain, where gray matter is displayed as gray. Left lateral, frontal, and left lateral views of the brain (Panels B, C, and D, respectively) are shown with varying degrees of gray matter removed to reveal white matter (yellow). The amygdala-hippocampal complex (Panel E) is shown viewed from above, with its anterior portion at the bottom of the panel (it is clear why this structure is named after the sea horse). The temporal lobe (Panel $F$ ) is shown in an anterior and slightly superior view; the posterior region is shown here as gray, the anterior region as yellow (anterior and posterior boundaries as defined for the superior temporal gyrus), and the temporal pole as red. The prominent ridge on the superior surface is Heschl's gyrus; the flat region posterior and lateral to it is the planum temporale (PT). 


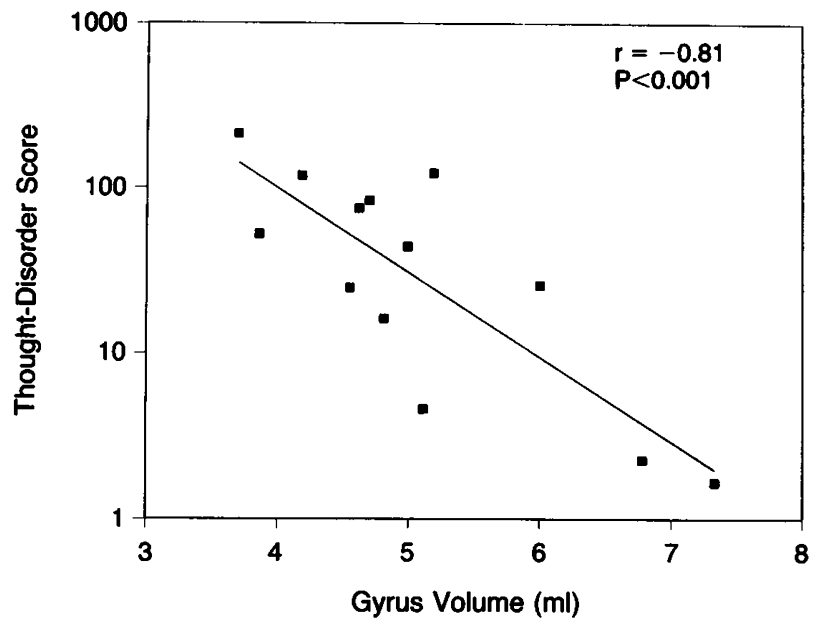

Figure 4. Volume of the Left Posterior Superior Temporal Gyrus in Relation to the Total Score for the Thought-Disorder Index ${ }^{35,36}$ in 13 Patients with Schizophrenia.

The thought-disorder score was not obtained for 2 of the 15 patients in the study.

time; both these improvements increase the likelihood of future clinical use. The precision of measurement is also excellent as judged by the agreement between our values and those in the literature (see Table 2 and other sources ${ }^{49-53}$. Since segmentation algorithms cannot currently be reliably applied to images obtained by spoiled-gradient-recalled acquisition, we sought to maximize the precision of manual measurement by using thin, $1.5-\mathrm{mm}$ slices, thus reducing error in measurement, and by objectively defining the regions of interest, allowing good interrater reliability. Our findings suggest that quantitative techniques to measure volume are essential to define the subtle abnormalities of schizophrenia.

The absence of any reduction in the volume of the entire brain or the temporal lobe is consistent with the results of our previous study, which examined the volume of a large part of the brain although not all of it, ${ }^{44,45}$ and with the results of Barta et al., ${ }^{10}$ who used manual segmentation and who also found no decrease in overall brain volume but localized reduction in the volume of the hippocampus and superior temporal gyrus. That some studies have reported reductions in the volume of the left temporal lobe ${ }^{14,15,59,60}$ whereas others have not ${ }^{10,44,45,61}$ suggests that the differences may be due to differences between subjects (e.g., in their sex or duration of illness) ${ }^{14,59}$ or between measurement techniques, especially if noncontiguous or thick slices were measured.

Although many studies using CT have reported enlarged lateral ventricles and an increased ventricle: brain ratio in patients with schizophrenia, ${ }^{62}$ we did not find any mean differences. Differences between study populations ${ }^{62}$ probably account for the findings of studies using CT or MRI that, like our present study with MRI, found no increases. ${ }^{44,45,59,60,63}$ Our study did, however, find evidence of more localized ventricular abnormality as manifested by enlargement of the left temporal horn, confirming previous studies using both MRI ${ }^{13,59,61,64}$ and postmortem examination. ${ }^{3,22}$ This enlargement was associated with localized reduction in the volume of the structures of the medial temporal lobe that surround the temporal horn, suggesting replacement of brain tissue by cerebrospinal fluid.

Reductions in the volume of the left segments of the anterior amygdala-hippocampal complex, superior temporal gyrus, and parahippocampal gyrus are compatible with MRI cross-sectional (area) measurements of the anterior amygdala-hippocampal complex $^{10-12,15}$ and parahippocampal gyrus ${ }^{15}$ and with postmortem studies reporting reductions in tissue in the hippocampus and parahippocampal gyrus ${ }^{1-3,7,8}$ and cellular disarray in the left amygdala ${ }^{65}$ and entorhinal cortex. ${ }^{6,66}$ These specific, localized volume reductions were not accompanied by reductions in the volume of overall brain or temporal-lobe tissue, suggesting further that schizophrenia, at least in the population that we studied, is associated with strategically localized rather than global volume reductions.

Thought disorder is a hallmark symptom of schizophrenia, ${ }^{25}$ and its characteristics in schizophrenia differ from its characteristics in other psychoses ${ }^{37}$ It is a symptom that Bleuler ${ }^{25}$ originally proposed as the primary feature of schizophrenia:

In this malady the associations lose their continuity. Of the thousands of associative threads which guide our thinking, this disease seems to interrupt, quite haphazardly, sometimes such single threads, sometimes a whole group, and sometimes even large segments of them. In this way, thinking becomes illogical and often bizarre. Furthermore, the associations tend to proceed along new lines . . . two ideas, fortuitously encountered, are combined into one thought, the logical form being determined by incidental circumstances.

The response of one of our patients to a Rorschach card illustrates the marked disturbance of associations and other forms of formal thought disorder:

in my mind to be someone, but . . . it just has a clear view, viewpoint on . . . when you stabilize, holding it with your thumbs and move your fingers, and blink your eyes, maybe. The K-complex of kindness, porphyria . . . the fine first . . . firm, fine, fast, fasting . . . cilia on the paramecium. . .

We found that the degree of formal thought disorder correlated with the reduction in volume of the left superior temporal gyrus, thus confirming and extending our previous study using $\mathrm{CT},{ }^{28}$ which showed an association between an increase in the left sylvian fissure and the presence of positive symptoms (hallucinations, delusions, and thought disorder), and the important documentation by Barta et al. ${ }^{10}$ of an association between auditory hallucinations and the volume of the superior temporal gyrus measured with MRI. Overall, these data are in agreement with our hypothesis ${ }^{28}$ that (right-handed) patients with schizophrenia have damage in the left temporal lobe, evident structurally as tissue loss and clinically as positive symptoms. ${ }^{18,28}$

This correlation accounted for 66 percent of the variance and may reflect damage to a zone (especially the planum temporale component) of great impor- 
tance to the semantic structure of language. ${ }^{54-58,67,68}$ Moreover, it seems to confirm Bleuler's prediction that thought disorder would ultimately be linked to a brain abnormality. We caution, however, that this zone may not be solely responsible for thought disorder; it may be a final common pathway. Furthermore, brain regions that we did not examine may also be important, although we note that the volume of our control region - the gray matter of the superior frontal gyrus - was not significantly different in our study groups, nor did it correlate with the degree of thought disorder (preliminary data from measurement of the gray matter of the cingulate gyrus show the same negative findings: the mean $[ \pm S D]$ volume in controls was $7.4 \pm 1.2 \mathrm{ml}$ in the left gyrus and $7.8 \pm 1.4 \mathrm{ml}$ in the right gyrus; in the patients it was $7.2 \pm 1.7 \mathrm{ml}$ in the left gyrus and $7.3 \pm 1.5 \mathrm{ml}$ in the right gyrus $(P=0.67$ and $\mathbf{P}=0.19$ ).

We hypothesize that the strong correlations among volume reductions of neuroanatomically interconnected structures such as the amygdala-hippocampal complex, parahippocampal gyrus, and superior temporal gyrus reflect damage to an interconnected neural network ${ }^{69-73}$ that is functionally important for associative links in memory. ${ }^{68,69,73-75}$ Many lines of evidence suggest that the hippocampus is important to storage and retrieval of memory and that memory is probably stored at neocortical sites in response to input arising from the hippocampus, ${ }^{73}$ with the superior temporal gyrus being especially important for auditory associative memory. Damage to this interconnected network could therefore result in difficulties in the storage and retrieval of auditory or language memory, particularly in the language-related domain in which the left posterior superior temporal gyrus, especially the planum temporale, is important. ${ }^{68,75}$ This difficulty may be manifested as an inability to maintain a proper gradient of strength of associational linkages, leading to thought disorder and, as described by Bleuler, ${ }^{25}$ "incidental" linkages.

The pattern of focal volume reductions on the left side of the brain does not support the dopamine hypothesis of schizophrenia, ${ }^{76,77}$ since dopamine projections are diffuse and their abnormalities have not been linked with localized reductions in tissue volume. As one alternative, we have proposed a model of dysregulation of neurotransmission regulated by the excitatory amino acid receptors identified by $N$-methyl-Daspartic acid (NMDA). ${ }^{17}$ This could account for the irritative, positive symptoms such as thought disorder and hallucinations that result from neural overactivation. Loss of brain tissue may result from neuronal death due to excessive activation (excitotoxicity) or from developmental abnormalities that accompany disruption of the formation of NMDA-receptor-guided neural pathways.

In conclusion, we view the finding of a specific association between schizophrenic thought disorder and loss of tissue from the left posterior superior temporal gyrus as a hopeful sign for research into this severely disabling disorder. It suggests that similar approaches will be able to uncover the roots of other clinical manifestations of this disease.

We are indebted to R. Scott Smith, Brian Chiango, Maureen Ainslie, I-han Chou, Marie Fairbanks, and Carla Kohlberger for technical and administrative support; to Mark Anderson and William Hanlon for assistance with computer programming; to Sandy Hall for photography; to Paul Nestor and Christine Waternaux for suggestions about statistical analysis; and to Brian O'Donnell, Dorothy Holinger, Philip Holzman, Deborah Levy, and Jennifer Haimson for editorial comments and suggestions.

\section{References}

1. Bogerts B. Zur Neuropathologie der Schizophrenien. Fortschr Neurol Psychiatr 1984;52:428-37.

2. Bogerts B, Meertz E, Schonfeldt-Bausch R. Basal ganglia and limbic system pathology in schizophrenia: a morphometric study of brain volume and shrinkage. Arch Gen Psychiatry 1985;42:784-91.

3. Brown R, Colter N, Corsellis JAN, et al. Postmortem evidence of structural brain changes in schizophrenia: differences in brain weight, temporal horn area, and parahippocampal gyrus compared with affective disorder. Arch Gen Psychiatry 1986;43:36-42.

4. Falkai P, Bogerts B. Cell loss in the hippocampus of schizophrenics. Eur Arch Psychiatry Neurol Sci 1986;236:154-61.

5. Falkai P, Bogerts B, Rozumek M. Limbic pathology in schizophrenia: the entorhinal region - a morphometric study. Biol Psychiatry 1988;24:51521.

6. Jakob H, Beckmann H. Gross and histological criteria for developmental disorders in brains of schizophrenics. J R Soc Med 1989;82:466-9.

7. Jeste DV, Lohr JB. Hippocampal pathologic findings in schizophrenia: a morphometric study. Arch Gen Psychiatry 1989;46:1019-24.

8. Colter N, Battal S, Crow TJ, Johnstone EC, Brown R, Bruton C. White matter reduction in the parahippocampal gyrus of patients with schizophrenia. Arch Gen Psychiatry 1987;44:1023.

9. Jakob H, Beckmann H. Prenatal developmental disturbances in the limbic allocortex in schizophrenics. J Neural Transm 1986;65:303-26.

10. Barta PE, Pearlson GD, Powers RE, Richards SS, Tune LE. Auditory hallucinations and smaller superior temporal gyral volume in schizophrenia. Am J Psychiatry 1990;147:1457-62.

11. DeLisi LE, Dauphinais ID, Gershon ES. Perinatal complications and reduced size of brain limbic structures in familial schizophrenia. Schizophr Bull 1988;14:185-91.

12. Suddath RL, Christison GW, Torrey EF, Casanova MF, Weinberger DR. Anatomical abnormalities in the brains of monozygotic twins discordant for schizophrenia. N Engl J Med 1990;322:789-94.

13. Bogerts B, Ashtari M, Degreef G, Alvir JM, Bilder RM, Lieberman JA. Reduced temporal limbic structure volumes on magnetic resonance images in first episode schizophrenia. Psychiatry Res 1990;35:1-13.

14. DeLisi LE, Hoff AL, Schwartz JE, et al. Brain morphology in first-episode schizophrenic-like psychotic patients: a quantitative magnetic resonance imaging study. Biol Psychiatry 1991;29:159-75. [Erratum, Biol Psychiatry 1991;29:519.]

15. Young AH, Blackwood DHR, Roxborough H, McQueen JK, Martin MJ, Kean D. A magnetic resonance imaging study of schizophrenia: brain structure and clinical symptoms. Br J Psychiatry 1991;158:158-64.

16. Faux SF, Shenton ME, McCarley RW, Nestor PG, Marcy B, Ludwig A. Preservation of $\mathrm{P} 300$ event-related potential topographic asymmetries in schizophrenia with use of either linked-ear or nose reference sites. Electroencephalogr Clin Neurophysiol 1990;75:378-91.

17. McCarley RW, Faux SF, Shenton ME, Nestor PG, Adams J. Event-related potentials in schizophrenia: their biological and clinical correlates and a new model of schizophrenic pathophysiology. Schizophr Res 1991;4:209-31.

18. Shenton ME, Faux SF, McCarley RW, et al. Correlations between abnormal auditory $\mathrm{P} 300$ topography and positive symptoms in schizophrenia: a preliminary report. Biol Psychiatry 1989;25:710-6.

19. DeLisi LE, Buchsbaum MS, Holcomb HH, et al. Increased temporal lobe glucose use in chronic schizophrenic patients. Biol Psychiatry 1989;25:83551 .

20. Wiesel FA, Wik G, Sjögren I, Blomqvist G, Greitz T, Stone-Elander S. Regional brain glucose metabolism in drug free schizophrenic patients and clinical correlates. Acta Psychiatr Scand 1987;76:628-41.

21. Posner MI, Early TS, Reiman E, Pardo PJ, Dhawan M. Asymmetries in hemispheric control of attention in schizophrenia. Arch Gen Psychiatry 1988;45:814-21.

22. Crow TJ, Ball J, Bloom SR, et al. Schizophrenia as an anomaly of development of cerebral asymmetry: a postmortem study and a proposal concerning the genetic basis of the disease. Arch Gen Psychiatry 1989;46:1145-50.

23. Crow TJ. The continuum of psychosis and its genetic origins: the sixty-fifth Maudsley lecture. Br J Psychiatry 1990;156:788-97.

24. Idem. Temporal lobe asymmetries as the key to the etiology of schizophrenia. Schizophr Bull 1990;16:433-43. 
25. Bleuler E. Dementia praecox or the group of schizophrenias. Zinkin H, trans. Monograph series on schizophrenia no. 1. New York: International Universities Press, 1950.

26. Filipek PA, Kennedy DN, Caviness VS Jr, Rossnick SL, Spraggins TA, Starewicz PM. Magnetic resonance imaging-based brain morphometry: development and application to normal subjects. Ann Neurol 1989;25:61-7.

27. Pfefferbaum A, Lim KO, Rosenbloom M, Zipursky RB. Brain magnetic resonance imaging: approaches for investigating schizophrenia. Schizophr Bull 1990;16:453-76.

28. McCarley RW, Faux SF, Shenton ME, et al. CT abnormalities in schizophrenia: a preliminary study of their correlations with P300/P200 electrophysiological features and positive/negative symptoms. Arch Gen Psychiatry 1989;46:698-708.

29. Spitzer RL, Endicott J. Schedule for affective disorders and schizophrenia - Life Time version. New York: New York State Psychiatric Institute, 1978.

30. Diagnostic and statistical manual of mental disorders. 3rd ed. rev.: DSMIII-R. Washington, D.C.: American Psychiatric Association, 1987.

31. Wechsler D. WAIS-R: manual: Wechsler adult intelligence scale-revised. New York: Harcourt Brace Jovanovich, 1981.

32. Hollingshead AB. Two factor index of social position. New Haven, Conn: Yale University Press, 1965.

33. Andreasen NC. Scale for the assessment of positive symptoms (SAPS) Iowa City: University of lowa College of Medicine, 1984.

34. Idem. Scale for the assessment of negative symptoms (SANS). Iowa City: University of Iowa College of Medicine, 1981.

35. Johnston MH, Holzman PS. Assessing schizophrenic thinking: a clinical and research instrument for measuring thought disorder. San Francisco: Jossey-Bass, 1979.

36. Solovay MR, Shenton ME, Gasperetti C, et al. Scoring manual for the Thought Disorder Index. Schizophr Bull 1986;12:483-96.

37. Shenton ME, Solovay MR, Holzman PS. Comparative studies of thought disorders. Il. Schizoaffective disorder. Arch Gen Psychiatry 1987;44:21-30.

38. Cline HE, Dumoulin CL, Hart HR Jr, Lorensen WE, Ludke S. 3D Reconstruction of the brain from magnetic resonance images using a connectivity algorithm. Magn Reson Imaging 1987;5:345-52.

39. Cline HE, Lorensen WE, Kikinis R, Jolesz FA. Three-dimensional segmentation of MR images of the head using probability and connectivity. J Comput Assist Tomogr 1990;14:1037-45.

40. Cline HE, Lorensen WE, Ludke S, Crawford CR, Teeter BC. Two algorithms for the three-dimensional reconstruction of tomograms. Med Phys 1988;15:320-7

41. Gerig G, Kikinis R, Kübler O. Significant improvement of MR image data quality using anisotropic diffusion filtering. Technical report BIWI-TR124. Zurich, Switzerland: Eidgenössischen Technischen Hochschule [ETH] 1990.

42. Kikinis R, Jolesz FA, Gerig G, et al. 3D Morphometric and morphometric information derived from clinical brain MR images. In: Hohne KH, Fuchs H, Pizer SM, et al., eds. 3D: Imaging in medicine. NATO ASI Series Vol. F60. Berlin, Germany: Springer-Verlag, 1990:441-54.

43. Perona $\mathbf{P}$, Malik J. Scale space and edge detection using anisotropic diffusion. In: Proceedings of the IEEE Workshop on Computer Vision, Miami, Fla., 1987. Washington, D.C.: IEEE Computer Society Press, 1987:16-22.

44. Shenton ME, Kikinis R, McCarley RW, Sandor T, Metcalf D, Jolesz FA. MRI in SZ: computer aided measures of brain \& CSF. Presented at the 145th American Psychiatric Association Annual Meeting, 1990. abstract.

45. Shenton ME, Kikinis R, McCarley RW, Metcalf D. Tieman J, Jolesz FA. Application of automated MRI volumetric measurement techniques to the ventricular system in schizophrenics and normal controls. Schizophr Res 1991;5:103-13.

46. Cline HE, Lorensen WE, Souza SP, et al. 3D Surface rendered MR images of the brain and its vasculature. J Comput Assist Tomogr 1991;15:344-51.

47. Daniels DL, Haughton VM, Naidich TP. Cranial and spinal magnetic resonance imaging: an atlas and guide. New York: Raven Press, 1987.

48. Zipursky RB, Lim KO, Sullivan EV, Brown BW, Pfefferbaum A. Widespread cerebral gray matter volume deficits in schizophrenia. Arch Gen Psychiatry 1992;49:195-205.

49. Boyd E. Organ weights from birth to maturity. In: Altman PL, Dittmer DS, eds. Growth including reproduction and morphological development. Biological handbooks. Washington, D.C.: Federation of American Societies for Experimental Biology, 1962:346.

50. Grant $R$, Condon $B$, Lawrence $A$, et al. Human cranial CSF volumes measured by MRI: sex and age influences. Magn Reson Imaging 1987;5:465-8.

51. Gur RE, Mozley PD, Resnick SM, et al. Magnetic resonance imaging in schizophrenia: I. Volumetric analysis of brain and cerebrospinal fluid. Arch Gen Psychiatry 1991;48:407-12.
52. Wyper DJ, Pickard JD, Matheson M. Accuracy of ventricular volume estimation. J Neurol Neurosurg Psychiatry 1979;42:345-50.

53. Duvernoy HM. The human hippocampus: an atlas of applied anatomy. Munich, Germany: J.F. Bergmann, 1988.

54. Geschwind N, Levitsky W. Human brain: left-right asymmetries in temporal speech region. Science 1968;161:186-7.

55. Galaburda AM, Corsiglia J, Rosen GD, Sherman GF. Planum temporale asymmetry, reappraisal since Geschwind and Levitsky. Neuropsychologia 1987;25:853-68.

56. Galaburda AM. Anatomical asymmetries. In: Geschwind N, Galaburda AM, eds. Cerebral dominance: the biological foundations. Cambridge, Mass.: Harvard University Press, 1984:11-25.

57. Steinmetz H, Rademacher J, Huang YX, et al. Cerebral asymmetry: MR planimetry of the human planum temporale. J Comput Assist Tomogr 1989; 13:996-1005.

58. Ojemann GA. Cortical organization of language. J Neurosci 1991;11:22817.

59. Johnstone EC, Owens DGC, Crow TJ, et al. Temporal lobe structure as determined by nuclear magnetic resonance in schizophrenia and bipolar affective disorder. J Neurol Neurosurg Psychiatry 1989;52:736-41.

60. Rossi A, Stratta P, D'Albenzio L, et al. Reduced temporal lobe areas in schizophrenia: preliminary evidences from a controlled multiplanar magnetic resonance imaging study. Biol Psychiatry 1990;27:61-8.

61. Kelsoe JR Jr, Cadet JL, Pickar D, Weinberger DR. Quantitative neuroanatomy in schizophrenia: a controlled magnetic resonance imaging study. Arch Gen Psychiatry 1988;45:533-41.

62. Shelton RC, Weinberger DR. X-ray computerized tomography studies in schizophrenia: a review and synthesis. In: Nasrallah HA, Weinberger DR, eds. The neurology of schizophrenia. Vol. 1 of Handbook of schizophrenia. Amsterdam: Elsevier Science, 1986:207-50.

63. Schwartzkopf SB, Olson SC, Nasrallah HA, Lynn MB, Mitra T. Reduced cerebral volume and increased third ventricular volume in schizophrenic patients: a quantitative magnetic resonance imaging study. Schizophr Res $1991 ; 4: 412$.

64. Degreef G, Wellington G, Alvir J, et al. Relationship of obstetric complications to brain pathomorphology as seen on MR scans in schizophrenia. Presented at the International Congress on Schizophrenia Research, Tucson, Ariz., 1991. abstract.

65. Kovelman JA, Scheibel AB. A neurohistological correlate of schizophrenia. Biol Psychiatry 1984;19:1601-21.

66. Arnold SE, Hyman BT, Van Hoesen GW, Damasio AR. Some cytoarchitectural abnormalities of the entorhinal cortex in schizophrenia. Arch Gen Psychiatry 1991;48:625-32.

67. Wernicke C. Der aphasische Symptomenkomplex. Breslau, Poland: Cohen and Weigart, 1874

68. Ojemann GA, Creutzfeldt $O$, Lettich E, Haglund MM. Neuronal activity in human lateral temporal cortex related to short-term verbal memory, naming and reading. Brain 1988;111:1383-403.

69. Witter MP, Amaral DG. Entorhinal cortex of the monkey. V. Projections to the dentate gyrus, hippocampus, and subicular complex. J Comp Neurol 1991;307:437-59.

70. Saunders RC, Rosene DL, Van Hoesen GW. Comparison of the efferents of the amygdala and the hippocampal formation in the thesus monkey. II. Reciprocal and non-reciprocal connections. J Comp Neurol 1988;271:185207.

71. Amaral DG, Insausti R, Cowan WM. Evidence for a direct projection from the superior temporal gyrus to the entorhinal cortex in the monkey. Brain Res 1983;275:263-77.

72. Rosene DL, Van Hoesen GW. The hippocampal formation of the primate brain: a review of some comparative aspects of cytoarchitecture and connections. In: Jones EG, Peters A, eds. Cerebral cortex. Vol. 6. Further aspects of cortical function, including hippocampus. New York: Plenum Press, 1987:345-456.

73. Squire LR, Zola-Morgan S. The medial temporal lobe memory system. Science $1991 ; 253: 1380-6$.

74. Sanghera MK, Rolls ET, Roper-Hall A. Visual responses of neurons in the dorsolateral amygdala of the alert monkey. Exp Neurol 1979;63:61026.

75. Penfield $\mathbf{W}$, Perot $\mathbf{P}$. The brain's record of auditory and visual experience: a final summary and discussion. Brain 1963;86:595-696.

76. Carlsson A. The current status of the dopamine hypothesis of schizophrenia. Neuropsychopharmacology 1988;1:179-86.

77. Weinberger DR. The pathogenesis of schizophrenia: a neurodevelopmental theory. In: Nasrallah HA, Weinberger DR, eds. The neurology of schizophrenia. Vol. 1 of Handbook of schizophrenia. New York: Elsevier Science, 1986:397-406. 